\title{
Wind effect on full-scale design of heliostat with torque tube
}

\author{
M. Mammar ${ }^{1,2, a}$, S. DjouimaA ${ }^{2}$, A. Hamidat $^{1}$, S. Bahria $^{1}$ and M. El Ganaoui ${ }^{3}$ \\ ${ }^{1}$ Centre de Développement des Energies Renouvelables, CDER, BP. 62 Route de l'Observatoire Bouzaréah, 16340 \\ Algiers, Algeria \\ 2 Applied Physics Energetics Laboratory, Physics Department, Material Sciences Faculty, Hadj Lakhdar University \\ Batna 1, Algeria \\ 3 LERMAB Laboratory, Lorraine University, IUT de Longwy, 54400 Cosnes et Romainm, France
}

Received 27 May 2016, Accepted 20 Octobre 2016

\begin{abstract}
Despite the importance of designing support structures for solar collectors, very little reliable work has been done to investigate the forces of the wind on heliostats of solar tower at real scale. Wind loads on heliostats are usually determined at low-speed wind tunnels scale, where the design full-scale Reynolds number cannot be reached. In the present study, measured data are used to validate the simulations at wind tunnel scale. Thereafter, by using the same method, three-dimensional numerical simulations of turbulent wind flow around a big heliostat of solar tower are performed. The obtained numerical results are presented for several elevation angles at normal operation and stow position. The results revealed that the known stow position (when the backside of the heliostat is facing the ground) is not the optimum position (other optimum elevation angles are discovered) especially with high wind speed, and the effect of torque tube is significant on heliostat mean wind loads.
\end{abstract}

Key words: Heliostat / full-scale / torque tube / mean wind loads / stow position

\section{Introduction}

The heliostat field is the main cost factor of solar tower plants. For a cost efficient dimensioning of the heliostats, the wind loads must be known [1]. Static (mean) wind loading of heliostats, including the forces and moments applied by steady wind, have a strong influence on the design of heliostat components [2].

The research about the wind loads on heliostats started in the end of the 1970s, and then in the following decades, the heliostat field array was extensively studied in the USA. However, before the 1990s, almost all of the work was limited to the wind tunnel test. Along with the wide spreading of commercial CFD software after the 1990s, numerical simulation was widely accepted and used in several industrial applications $[3,4]$.

Reference [5] introduced a design method by define extensively wind loads on flat heliostats through boundary layer wind tunnel tests [3] studied the gap effects of the wind load on heliostats by wind tunnel tests and numerical simulation. The results showed that the gap size effects due to wind load are no need to take into account in design of heliostats.

\footnotetext{
${ }^{\mathrm{a}}$ Corresponding author: m.mammar@cder.dz
}

Reference [4] studied by wind tunnel tests and numerical simulation the wind-induced dynamic response and fluctuating wind pressure characteristics of heliostats [1] published two important studies: wind loads on heliostats and photovoltaic trackers at various Reynolds numbers, and the second is about the wind loads on heliostats and photovoltaic trackers of various aspect ratios at wind tunnel scale. Later [6], presented the last work about the autonomous light-weight heliostat with rim drives, by describing the wind load assumptions, the mechanical structure, the drives and the control of the new heliostat concept.

Wind tunnel measurements that have been published so far have all been performed at Reynolds numbers (Re) considerably below the maximum values that can occur in reality [7]. Hence, computational fluid dynamics (CFD) became more required to understand the aerodynamic behaviour and wind loading on heliostat at real scale [3]. However, a number of questions as following are remained imperfectly [4]: what is the wind load on heliostat at real scale and for high wind speed? At what wind speed levels does significant heliostat movement occur? What is the relationship of the elevation angle of heliostat on air movement? At what wind speed and what elevation angles does the beam quality become unacceptable from an operational standpoint? What is the optimum elevation 
angle that have the minimum of static (mean) pressure moment?

In this paper, we performed firstly numerical tests on the aerodynamic loads of heliostat at wind tunnel scale. The obtained numerical results are compared with those of available measurement in order to confirm the reliability of meshing method and selected turbulence model. After that, we performed a series of numerical tests to gather information on the aerodynamic loads on big heliostat at real scale. Understanding the aerodynamic behaviour and loading of our heliostat design enabled systems to be designed to avoid the cost of the heliostat damage and failure [2].

\section{Wind tunnel scale CFD investigation}

The used wind tunnel at the Fluid Mechanics Laboratory was an open loop in draft wind tunnel. This type of tunnel uses suction at the tunnel exit to create flow through the test section [2]. The coordinate system in this study is defined as Figure 1.

\subsection{Specification of the system}

The first set of simulation model is constructed to identify the aerodynamic loads on a single isolated heliostat at wind tunnel scale. These initial tests are needed to validate the setup of meshing, turbulence model, and data acquisition system against experimental values obtained from NASA Ames Fluid Mechanic Laboratory.

A scale model of our heliostat was constructed (mirror plane size $=200 \mathrm{~mm} \times 200 \mathrm{~mm} \times 5 \mathrm{~mm}$ ), supporting pillar with diameter $D=20 \mathrm{~mm}$ and the vertical distance from the ground to the hinge axis $H=150 \mathrm{~mm}$.

Elevation angles $(\alpha)$ tested: $0,15,30,45,60,75,90$ degrees.

Where the elevation angle $(\alpha)$ is the angle between the mirror plane and the ground surface (Fig. 1).

The definitions of the wind load coefficients are according to $[5]$ :

$$
\begin{aligned}
F_{x} & =C_{F x} \frac{\rho}{2} V^{2} A \\
F_{z} & =C_{F z} \frac{\rho}{2} V^{2} A \\
M_{y} & =C_{M y} \frac{\rho}{2} V^{2} A H
\end{aligned}
$$

where $V$ is the air velocity $\left[\mathrm{m} . \mathrm{s}^{-1}\right], A$ is the mirror area $\left[\mathrm{m}^{2}\right], \rho$ is the air density $\left[\mathrm{kg} \cdot \mathrm{m}^{-3}\right], C_{F x}$ is the drag force coefficient, $C_{F z}$ is the lift force coefficient and $C_{M y}$ is moment force coefficient. The moment coefficient $C_{M y}$ is calculated with respect to the hinge height axis $H$ (Fig. 1).

\subsection{Numerical study}

\subsubsection{Governing equations and turbulence model}

The flow could be reasonably treated as incompressible flow. In addition, it was assumed that the tempera- ture field had no considerable effects on the pressure or velocity field [3]. Consequently, only continuity, moment and turbulence equations were involved in the numerical study. The numerical simulation was performed on the steady RANS equations using the commercial CFD code ANSYS Fluent 15.0, which uses the control volume method.

For the problem analysed in this paper, standard $k-\varepsilon$ turbulent model with wall function is selected. The $k-\varepsilon$ model is a two-equation model, which includes two transport equations to describe the turbulent properties of the flow: the turbulent kinetic energy $\mathrm{k}$ and the turbulent dissipation rate $\varepsilon$.

The choice of the standard $k-\varepsilon$ model was made based on a previous extensive validation studies for the aerodynamics of a single object (Heliostat, building, cars). In paper [8] the author concluded that standard $k-\varepsilon$ model is of satisfactory accuracy for studying wind loads on heliostat. In References $[9,10] k-\varepsilon$ turbulence model was used to simulate the flow field around two adjacent buildings, and Beijing Olympic Stadium. The papers [11,12] proved the high performance of standard $\mathrm{k}-\varepsilon$ model for cyclist and cube aerodynamics analysis. All these studies showed that $k-\varepsilon$ model has the accurate prediction of mean wind loads. Standard $k-\varepsilon$ model equations of incompressible flow are as following:

- Continuity equation:

$$
\frac{\partial u_{i}}{\partial x_{i}}=0
$$

- Momentum equation:

$$
\frac{\partial u_{i}}{\partial t}+u_{j} \frac{\partial u_{i}}{\partial x_{j}}=-\frac{1}{\rho} \frac{\partial p}{\partial x_{i}}+\nu \frac{\partial^{2} u_{i}}{\partial x_{i} \partial x_{j}}+g_{i}
$$

where $\nu=\frac{\mu}{\rho}$ is the kinematic viscosity and $\mu$ is the dynamic viscosity.

In turbulent flow $u_{i}$ and $p$ are written as following:

$$
u_{i}=U_{i}+u_{i}{ }^{\prime}, \quad p=P+p^{\prime}
$$

$U_{i}$ is the mean velocity, $P$ is the mean pressure, $u_{i}{ }^{\prime}$ and $p^{\prime}$ are the fluctuating parts.

Where:

$$
\begin{aligned}
\bar{u}_{i} & =U_{i}, \quad \bar{u}_{i}^{\prime}=0 \\
\bar{p} & =P, \quad \bar{p}^{\prime}=0
\end{aligned}
$$

By introducing Equation (6) into (4) and (5) we find the following equations:

$$
\begin{gathered}
\frac{\partial U_{i}}{\partial x_{i}}=0 \\
\frac{\partial U_{i}}{\partial t}+\frac{\partial\left(U_{i} U_{j}\right)}{\partial x_{j}}=-\frac{1}{\rho} \frac{\partial P}{\partial x_{i}}+\frac{\partial}{\partial x_{j}}\left(2 \nu S_{i j}-u_{i}{ }^{\prime} u_{j}^{\prime}\right)+g_{i}
\end{gathered}
$$

Where $S_{i j}$ is the mean strain-rate tensor

$$
S_{i j}=\frac{1}{2}\left(\frac{\partial U_{i}}{\partial x_{j}}+\frac{\partial U_{j}}{\partial x_{i}}\right)
$$




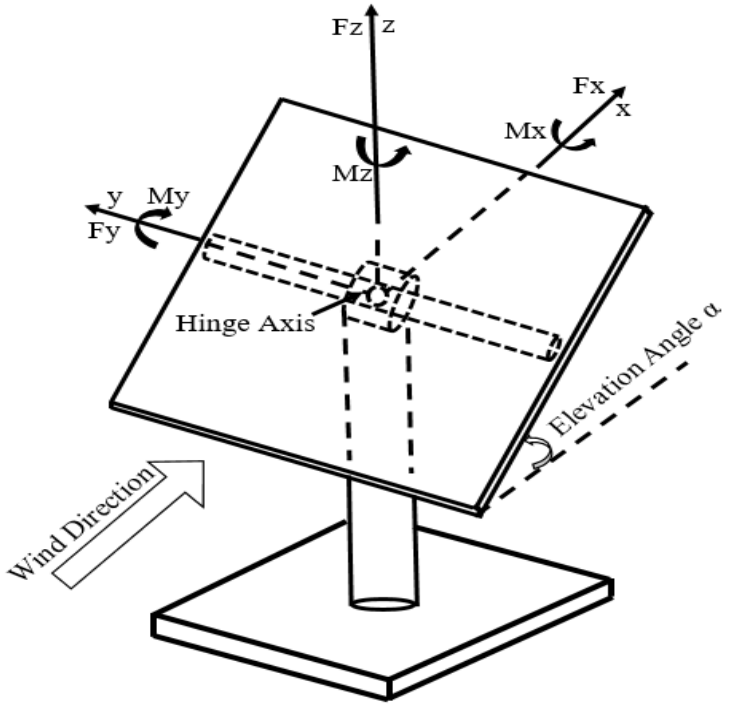

(a)

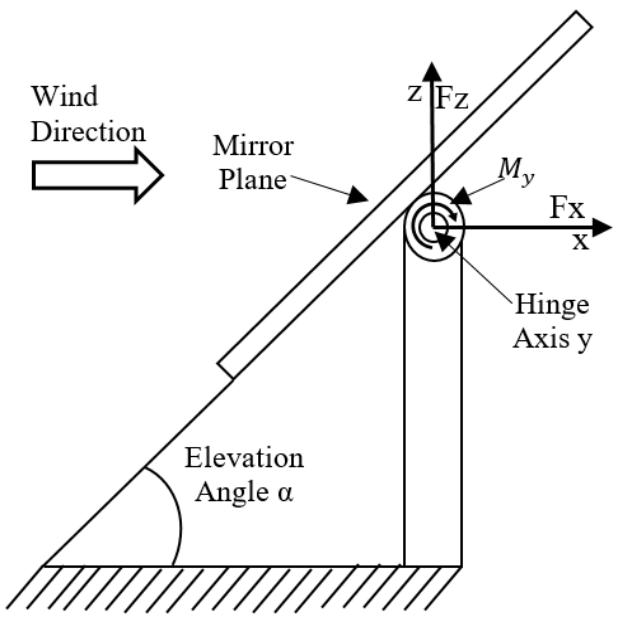

(b)

Fig. 1. Coordinate system of heliostat model: (a) generic view (b) side view.

The investigated wind loads are:

$F_{x}$ drag (horizontal) wind force $[\mathrm{N}]$.

$F_{z}$ lift (vertical) wind force $[\mathrm{N}]$.

$M_{y}$ wind force moment about elevation axis [N.m].

By introducing Equation (9) into (10):

$$
\frac{\partial U_{i}}{\partial t}+U_{j} \frac{\partial U_{i}}{\partial x_{j}}=-\frac{1}{\rho} \frac{\partial P}{\partial x_{i}}+\frac{\partial}{\partial x_{j}}\left(\nu \frac{\partial U_{i}}{\partial x_{j}}-u_{i}^{{ }^{\prime} u_{j}^{\prime}}\right)+g_{i}
$$

The Reynolds stresses is related to the turbulent viscosity as following:

$$
-u_{i}{ }^{\prime} u_{j}^{\prime}=2 \nu_{t} S_{i j}-\frac{2}{3} k \delta_{i j}
$$

where $\nu_{t}$ is kinetic eddy viscosity, and $\delta_{i j}$ is the Kronecker delta. The turbulence kinetic energy, $k$, is defined as following:

$$
k=\frac{1}{2} u_{i}{ }^{\prime} u_{i}^{\prime}
$$

The turbulence kinetic energy, $k$, and its rate of dissipation, $\varepsilon$, are obtained from the following transport equations:

$$
\frac{\partial k}{\partial t}+U_{j} \frac{\partial k}{\partial x_{j}}=\tau_{i j} \frac{\partial U_{i}}{\partial x_{j}}-\varepsilon+\frac{\partial}{\partial x_{j}}\left[\left(\nu+\frac{\nu_{t}}{\sigma_{k}}\right) \frac{\partial k}{\partial x_{j}}\right]
$$

And,

$\frac{\partial \varepsilon}{\partial t}+U_{j} \frac{\partial \varepsilon}{\partial x_{j}}=C_{1 \varepsilon} \frac{\varepsilon}{k} \tau_{i j} \frac{\partial U_{i}}{\partial x_{j}}-C_{2 \varepsilon} \frac{\varepsilon^{2}}{k}+\frac{\partial}{\partial x_{j}}\left[\left(\nu+\frac{\nu_{t}}{\sigma_{\varepsilon}}\right) \frac{\partial \varepsilon}{\partial x_{j}}\right]$

In these equations, $\tau_{i j}=-u_{i}{ }^{\prime} u_{j}{ }^{\prime}$ is known as the Reynolds stress tensor for constant density. The kinetic eddy viscosity $\nu_{t}$ is obtained by $k$ and $\varepsilon$ through the equation:

$$
\nu_{t}=C_{\mu} \frac{k^{2}}{\varepsilon}
$$

The corresponding four model constants are:

$$
C_{1 \varepsilon}=1.44, C_{2 \varepsilon}=1.92, C_{\mu}=0.09, \sigma_{k}=1.0, \sigma_{\varepsilon}=1.3
$$

These default values have been determined to work fairly well for a wide range of wall-bounded and free shear flows.

\subsubsection{Boundary conditions}

Both the wind flow velocity and turbulence intensity profiles at the inlet of the wind tunnel are shown in the following graphs (Figs. 2a and 2b).

The wind tunnel velocity profile at the inlet has free stream velocity of $18.2 \mathrm{~m} . \mathrm{s}^{-1}$ (Fig. 2a). The outlet boundary was set as pressure outlet $0 \mathrm{~Pa}$. Surface of the heliostat and the bottom was set as wall. In addition, there was a symmetry boundary at the top, the right and the left sides to represent the external flow around the heliostat. The density and dynamic viscosity of air are constant $\rho=1.22 \mathrm{~kg} \cdot \mathrm{m}^{-3}$ and $\mu=17.894 \times 10^{-6} \mathrm{~Pa} . \mathrm{s}$ respectively. In $k-\varepsilon$ model, the profiles of turbulent kinetic energy and turbulent dissipation rate in the inlet can be computed as following [13]:

- Turbulent kinetic energy: $k=\frac{3}{2}(U I)^{2}$, where $U$ is the mean value of velocity.

- Turbulent dissipation rate: $\varepsilon=0.09 \frac{k}{\beta \nu}$, where $\beta$ is the turbulent viscosity ratio.

\subsubsection{Meshing and solve method}

Figure 3 shows 3 -D computer model of heliostat. The computational domain is extended to $40 \mathrm{~L} \times 10 \mathrm{~L} \times$ 


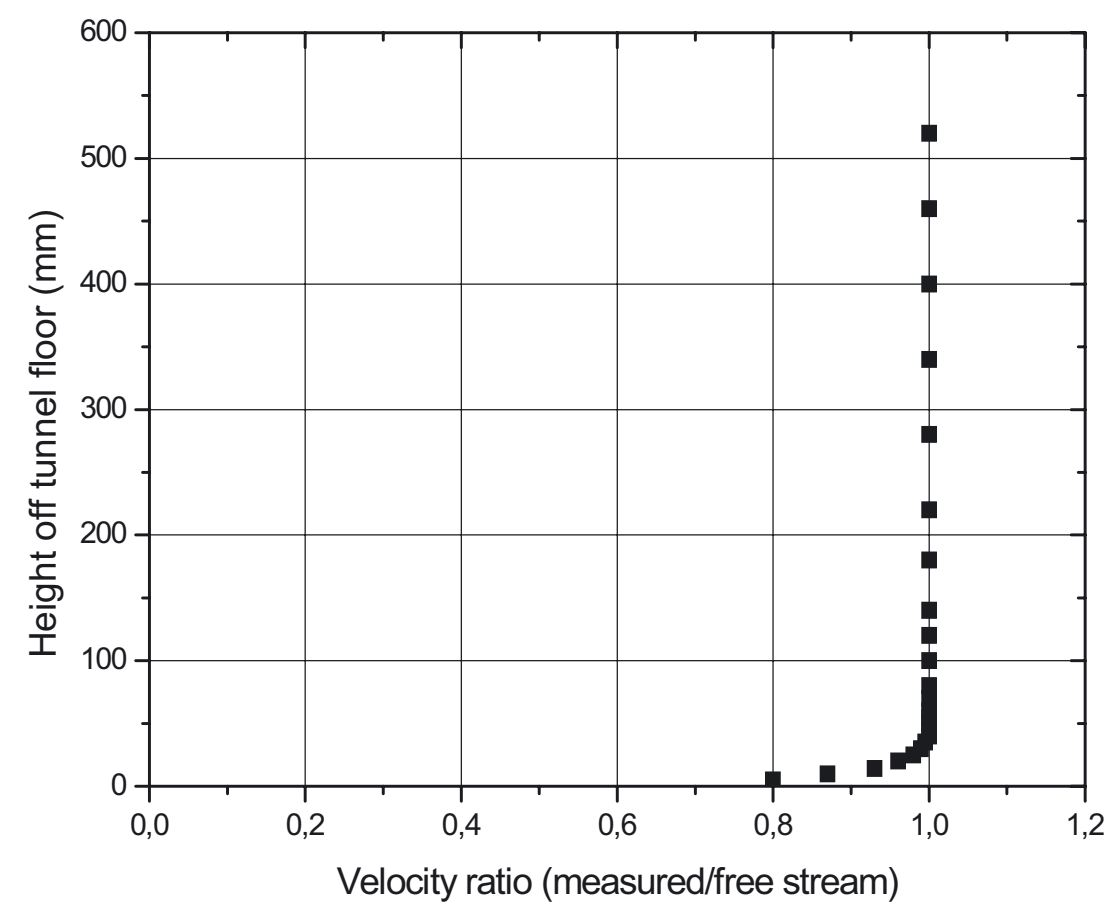

(a)

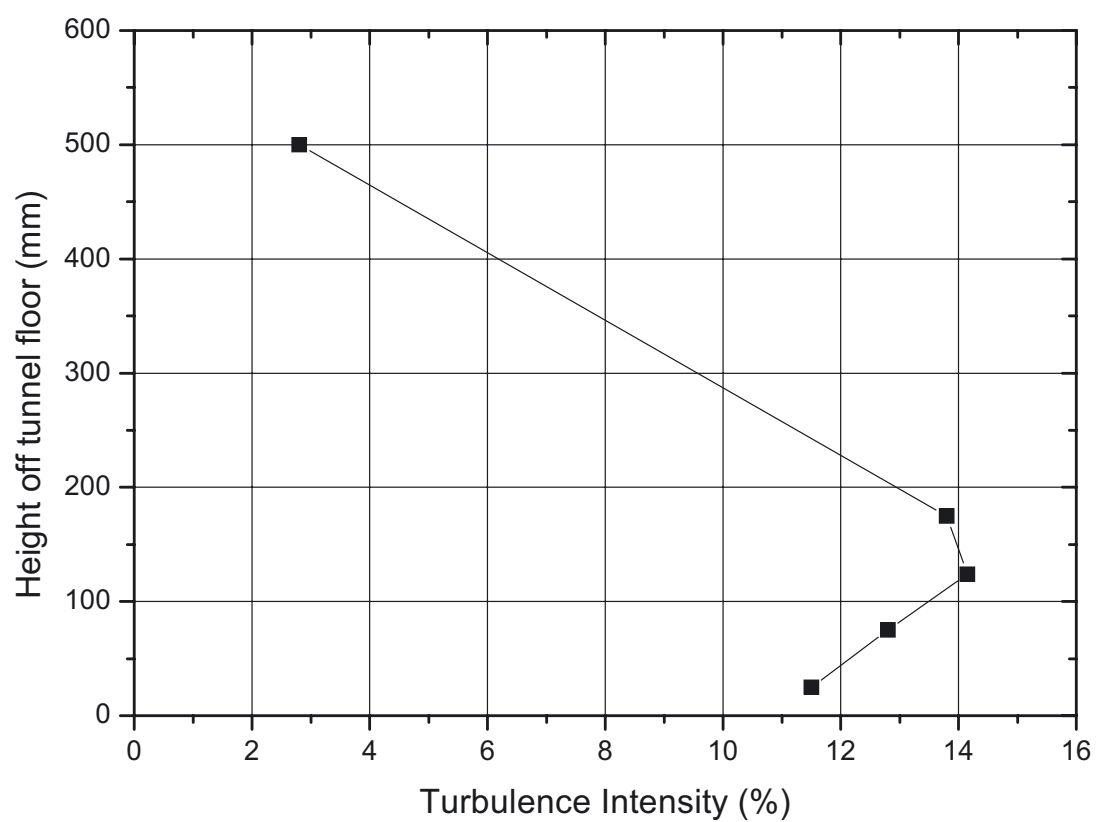

(b)

Fig. 2. (a) Inlet velocity profile of wind tunnel (NASA Ames, 2011). (b) Inlet turbulence intensity profile of wind tunnel (NASA Ames, 2011).

$10 \mathrm{~L}$ in the stream-, cross-and span-wise directions respectively. Where $\mathrm{L}$ is the characteristic length and equals to heliostat length $0.2 \mathrm{~m}$ in the current geometry.

The physical reasons for using large domain dimensions in the current study is to avoid the blockage effects. Small distances between the object and boundaries can cause large blockage effects that result inaccurate aerodynamic loading. This computational domain is adopted in many studies of wind load on different structures and the far-field boundary layer location is justified $[11,12,14]$.

Extensive grid refinement tests for each elevation angle are conducted in order to obtain a solution which describes the fluid flow and forces. The tetrahedral mesh is suited for each case of elevation angle and respect to the dimension of the problem. In order to capture the flow structures in the near of the mirror plane, mesh 


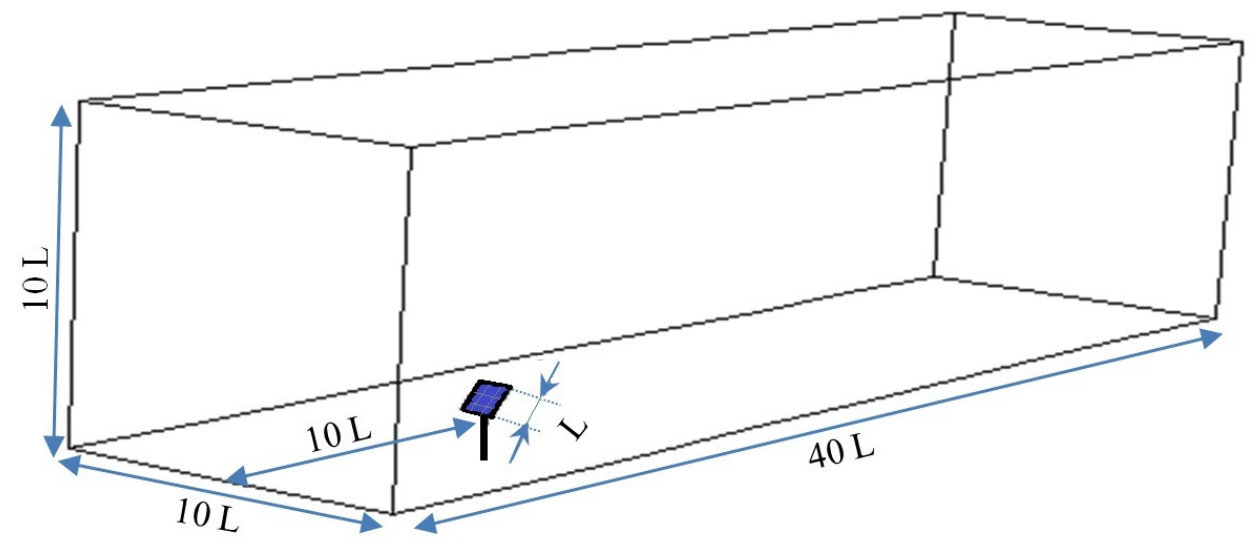

Fig. 3. Computational domain of heliostat.

requirements are higher in these zones. However, the construction of the mesh is quite dense near the heliostat [14].

Grid independence was conducted by comparing the pressure distribution on the mirror plane (facet) from the results of different grids of $N_{1}=900000$ cells, $N_{2}=1400000$ cells, $N_{3}=1850000$ cells and $N_{4}=$ 2300000 cells (Fig. 4).

It is desirable that the grid refinement factor $r=$ $\left(N_{\text {fine }} / N_{\text {coarse }}\right)^{\frac{1}{3}}$ be greater than 1 . Let $r_{12}=\left(N_{2} / N_{1}\right)^{\frac{1}{3}}$, $r_{23}=\left(N_{3} / N_{2}\right)^{\frac{1}{3}}, r_{34}=\left(N_{4} / N_{3}\right)^{\frac{1}{3}}$, the grid refinement factors in this study are $r_{12}=1.15, r_{23}=1.097, r_{34}=$ 1.075 .

The minimum cell size $\Delta l_{\text {min }}$ decreases by increasing the total number $\mathrm{N}$ of grid cells (where $0.002 \mathrm{~m} \leq \Delta l_{\text {min }} \leq$ $0.005 \mathrm{~m}$ for all the grids).

The final grid used in this study contained approximately 230000 tetrahedral cells, with typical minimum cell size of $\Delta l_{\min }=0.002 \mathrm{~m}$ (adjacent cell size) and maximum size of $\Delta l_{\max }=0.5 \mathrm{~m}$ (Fig. 5a). This fine mesh is necessary to be able to capture aerodynamic effects in this important region.

The use of this mesh density allows us to apply standard $k-\varepsilon$ model with standard wall function in the range of $25<y^{+}<250$ (Fig. 5b).

The simulations were performed using the control volume method and Pressure--velocity coupling was taken care of by the SIMPLE algorithm.

The second order upwind scheme was used for spatial discretization. Convergence was obtained when residuals reached $10^{-4}$ for continuity and momentum, $10^{-5}$ for turbulent kinetic energy and turbulence dissipation rate.

\subsection{Validation of the numerical model}

Series of simulations are performed to test the accuracy of the numerical model and observe the aerodynamic effect on heliostat reflector. The drag and lift coefficients at different elevation angles are calculated and compared with experimental measurements.
This velocity profile does not allow for Reynolds number matching between wind tunnel test conditions and real world operational conditions. However, this was the maximum permissible velocity for the model construction used during these tests [2]. Additionally, it was shown that coefficients do not vary significantly with velocity in this set of experiments, which validates work by [16].

The elevation angle $\alpha=90^{\circ}$ presents the maximum drag force $C_{F x}$ and it decreases by moving the heliostat toward the horizontal position $\alpha=0^{\circ}$ (Fig. 6). However, the absolute value of lift coefficient $C_{F z}$ is small at $\alpha=90^{\circ}$, as well as, to the stow position $\alpha=0^{\circ}$ where the surface of the heliostat is facing the ground. Lift coefficient $C_{F z}$ increases by approaching to the position of $25^{\circ}$, where the maximum absolute is $C_{F z}=1.21$, see Figure 7 .

By comparing the present computation results of standard $k-\varepsilon$ with the available experimental measurements [2], we found that the CFD modelled loads matched reasonably well (though not perfectly) with our wind tunnel data. This improves our confidence in using CFD for other analyses, which proves the accuracy of the present numerical method and the turbulence model performance used herein [14].

According to textbooks and industry references, the accepted drag coefficient for a flat plate perpendicular to the flow is $C_{F x}=1.28$ [2]. The measured drag coefficient was $C_{F x}=1.285$. The predicted drag coefficient for heliostat model at wind tunnel scale at the elevation angle $\alpha=90^{\circ}$ is matching very well with the theoretical and the experimental values (Fig. 6).

The agreements between computed and measured aerodynamic coefficients are mainly due to take on consideration profiles of velocity and the turbulence intensity at the inlet of the domain. However, the turbulent kinetic energy and dissipation rate profiles at the inlet are computed from velocity and turbulence intensity profiles. It is well-known that the inlet profiles in wind engineering plays an important role on flow development and more importantly on the wind loading. 


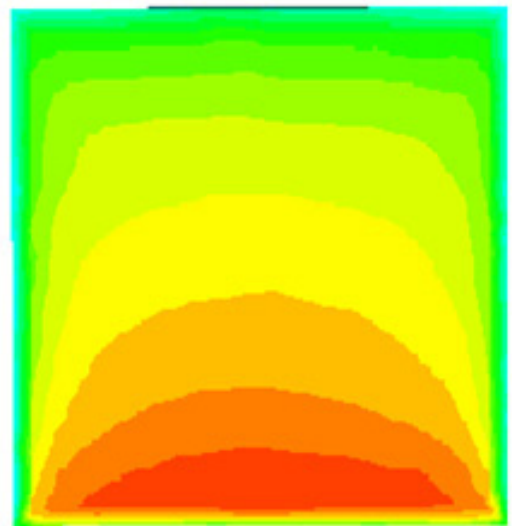

(a)

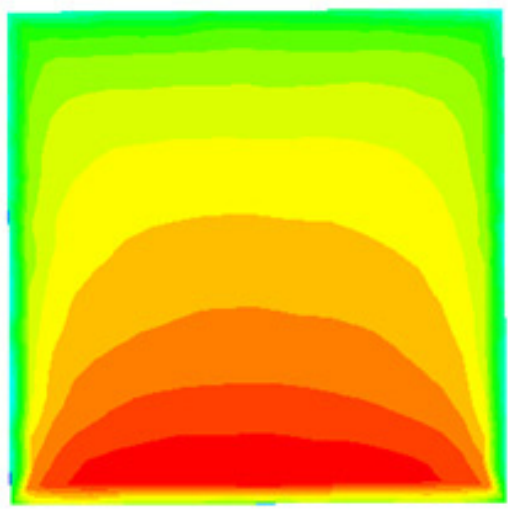

(c)
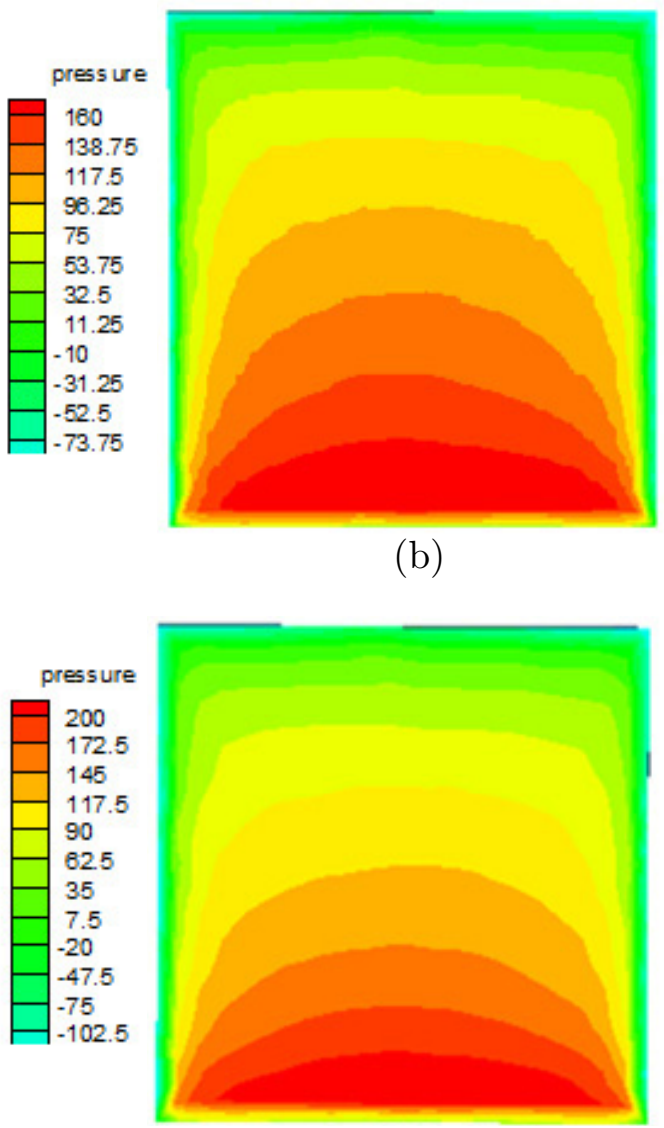

(d)

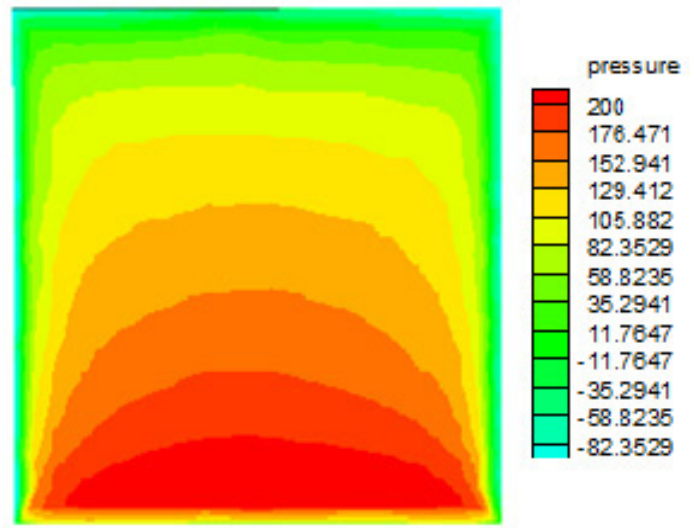

(b)

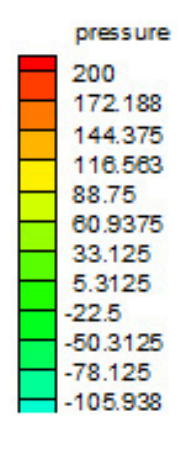

Fig. 4. Conducted grid independence study by comparing the pressure distribution (Pa) on mirror plane. (a) $N_{1}=900000$ cells. (b) $N_{2}=1400000$ cells. (c) $N_{3}=1850000$ cells. (d) $N_{3}=2300000$ cells.

\section{Full-scale CFD investigation}

The Re numbers are much higher for heliostats at real scale then heliostats at wind tunnel scale. Therefore, a typical, big heliostat with $123.84 \mathrm{~m}^{2}$ area (Fig. 5c) was investigated [1]. The main specifications are: h height of mirror plane $9.6 \mathrm{~m}$; b width of mirror plane $12.9 \mathrm{~m}, \mathrm{H}$ height of elevation axis $5.4 \mathrm{~m}$ and d diameter of torque tube $0.6 \mathrm{~m}$.

The determination of the Re dependency in atmosphere at full-scale is hardly possible because the appearance of the needed high wind speeds is random and not predictable. Investigations in a wind tunnel at real scale would demand a huge wind tunnel, which is not available. Measurements in conventional wind tunnels would be relatively cheap, but the needed Re cannot be reached [1]. Hence, we use the same numerical method shown before to estimate the mean quantities of loads coefficients, pressure forces, pressure moments and pressure field for the heliostat at real scale.

Truly uniform flow very rarely exists in nature $[2,17]$. According to the literature and responds to the study region (typical region for heliostat field), a function was used in this study to model the inlet velocity profile:

$$
\frac{u}{u_{r}}=\left(\frac{h}{h_{r}}\right)^{0.15}
$$

where $u_{r}$ refer to reference velocity and $h_{r}$ refer to reference height $10 \mathrm{~m}$. The turbulent intensity is $10 \%$. Outlet boundary condition is the relative gauge pressure $0 \mathrm{~Pa}$.

The bottom side and the surface of the heliostat structure are all smooth, no penetrations and no-slip walls. The top surface and the two side surfaces are set as free slip boundaries [8]. In reality, the mirror plane is divided by thin gaps between the facets but these are of negligible influence on the wind loads as [3] have shown.

\subsection{Load coefficients}

In practice, the heliostat is used in an array consisting of a number of similar units, and the design wind loads should be determined for such a configuration. However, loads on an isolated reflector are informative for characterizing the baseline performance [18]. The isolated heliostat was tested with torque tube (on the backside of heliostat mirror) and with aspect ratio of the surface plane 


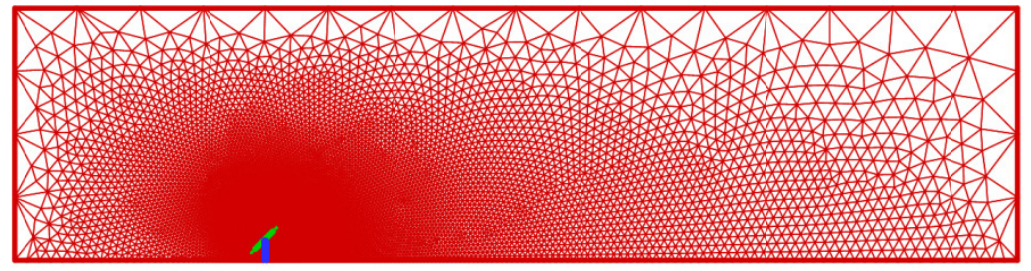

(a)
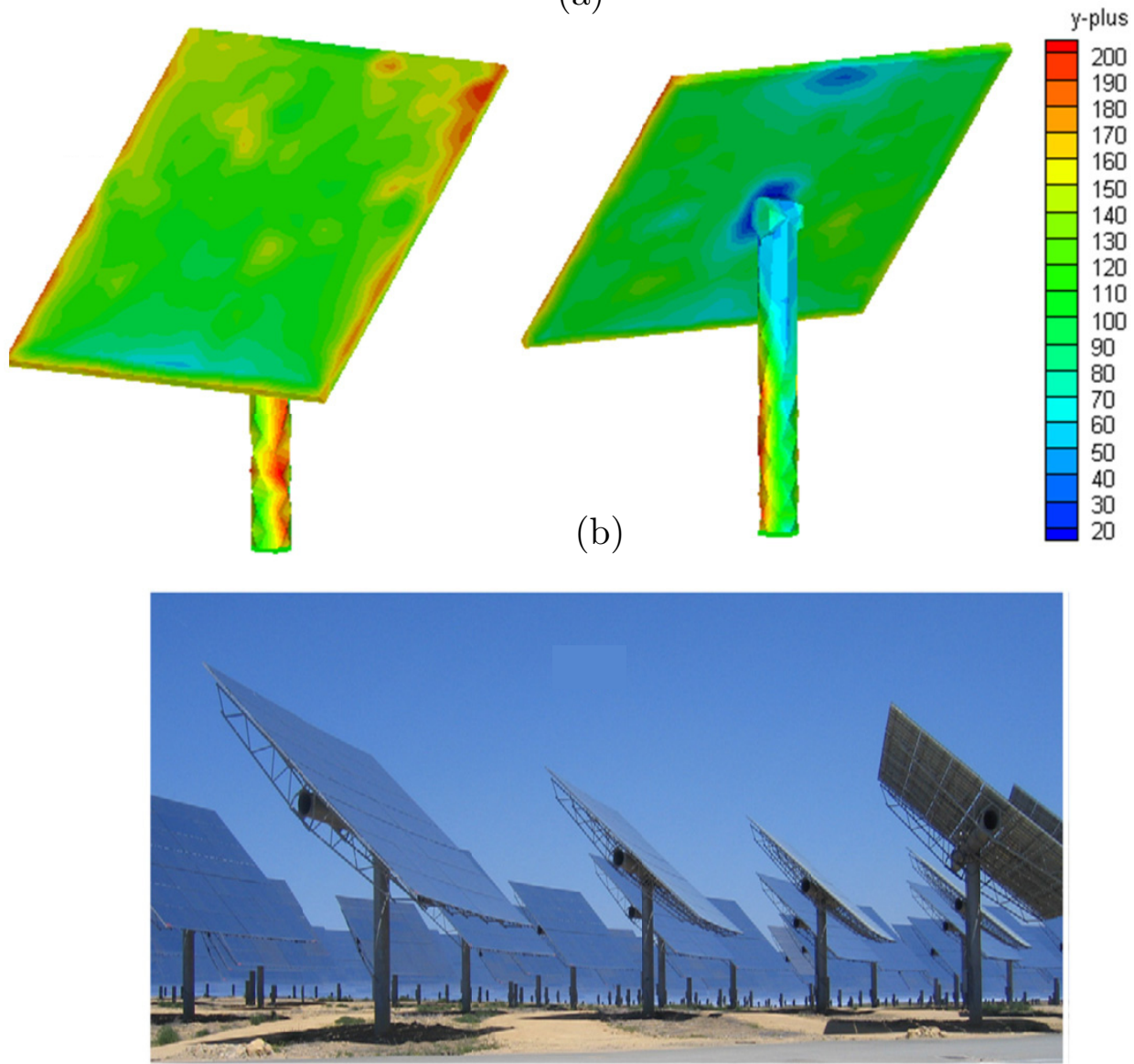

(c)

Fig. 5. (a) Example of mesh distribution at position $\alpha=45^{\circ}$ with 2300000 cells. (b) Dimensionless distance to wall $y+$ for the considered mesh. (c) Heliostats with surface mirror plane of $123.84 \mathrm{~m}^{2}$.

(width to height) of about 1.34. The yaw angle is 0 degrees, and the approach wind is perpendicular to $\mathrm{z}$ axis. Note that the test configuration relative to the wind was calculated at elevation angles between +90 and -90 degrees for all the coefficients $C_{F x}, C_{F z}, C_{M y}$.

The obtained results of drag, lift, moment mean coefficients at different elevation angles for full-scale heliostat with torque tube are presented in Figure 8.

All tested heliostats were nearly square in shape that had essentially the same load coefficients (Figs. 6 and 7); however, the influence of other shapes or aspect ratios is important $[4,19,20]$. With adopted heliostat, The effect of aspect ratio on the drag coefficient $C_{F x}$ appears significantly in Figure 8, for example, $C_{F x}=1.1$ at $\alpha=90^{\circ}$ (where $C_{F x}=1.28$ at $\alpha=90^{\circ}$ for square shape), in the meantime the effect of torque tube and the vertical tube is limited at this position.

The absolute value of lift coefficient of the positive angles is smaller than the one of negative angles, for example, $\left|C_{F z}\left(15^{\circ}\right)\right|=1.3<C_{F z}\left(-15^{\circ}\right)=1.48$, at this elevation angles the difference is more notable than other angles.

The effect of the torque tube is more apparent for the vertical force than for the horizontal force. The torque tube does not necessarily worsen the wind loads, for example, the vertical force component for a range of elevation angles from $0^{\circ}$ to $90^{\circ}$ is slightly reduced with the torque tube.

The influence of torque tube and the vertical tube appear significantly for moment coefficient $C_{M y}$. For a 


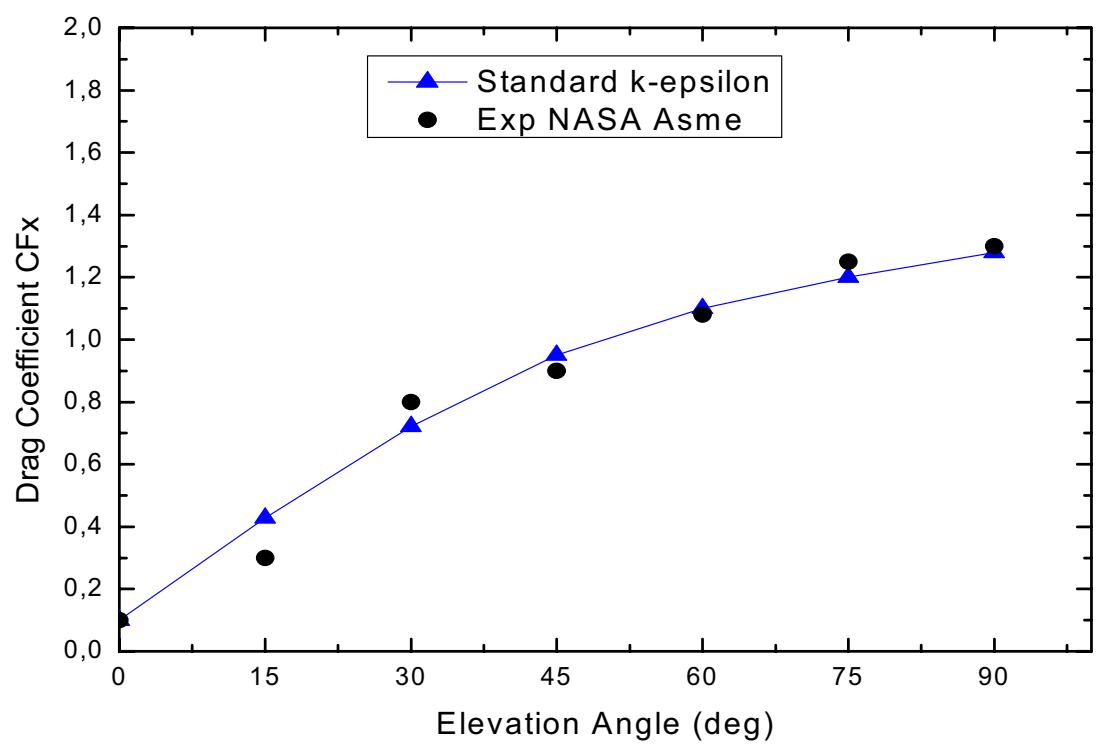

Fig. 6. Predicted and measured drag coefficient for different elevation angles for heliostat model at wind tunnel scale.

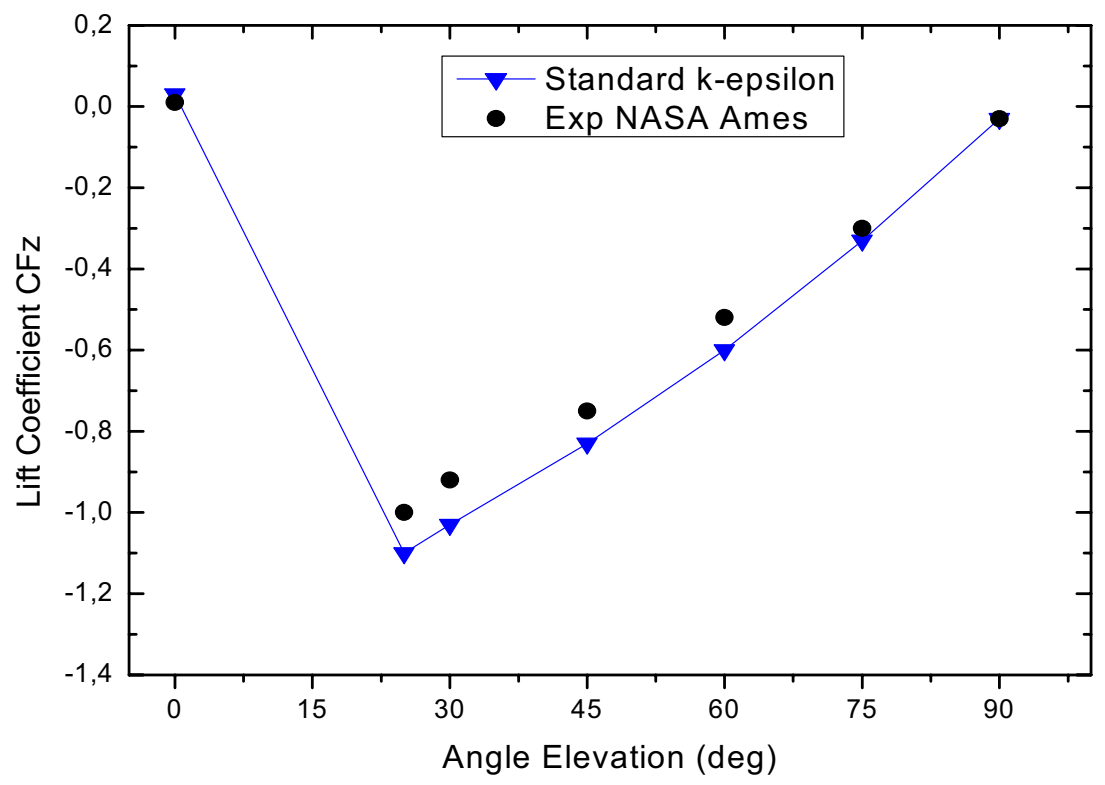

Fig. 7. Predicted and measured lift coefficient for different elevation angles for heliostat model at wind tunnel scale.

range of elevation angles from $-90^{\circ}$ to $-45^{\circ}$ and from $0^{\circ}$ to $90^{\circ}$, the coefficient moment $C_{M y}$ has negative values. However, from $-45^{\circ}$ to $0^{\circ}$, it has positive values and the moment force operates in the opposite direction, where the absolute momentum coefficient has the peak at $15^{\circ}$ and $-15^{\circ}$. The existence of these two tubes, at the front or the backside of mirror plane, helps to create a difference of pressure distribution between the high part and the low part of the mirror plane.

\subsection{Mean drag and lift pressure forces}

Results are presented for mean values of drag and lift pressure forces at elevation angles from $-90^{\circ}$ to $+90^{\circ}$ and for reference wind speeds of $5,10,15$, and $20 \mathrm{~m} . \mathrm{s}^{-1}$ (Tabs. 1 and 2).

With respect to the wind speed, it can be expected from the definition of wind loads that forces have a quadratic dependence on this parameter and indeed the data in Tables 1 and 2 approve this. With respect to elevation angle, the data suggests a linear dependence with $\cos \alpha$, however, it is easily ascertained how the interaction of these parameters influence the forces generated.

It can be seen from the results presented in Tables 1 and 2 that the magnitudes of drag and lift force vary extensively as the increase of elevation angles and wind speeds. The bigger the wind velocity is the bigger the drag and the absolute lift forces are. The bigger the absolute elevation angle is the bigger the drag force is. 
M. Mammar et al.: Mechanics \& Industry 18, 312 (2017)

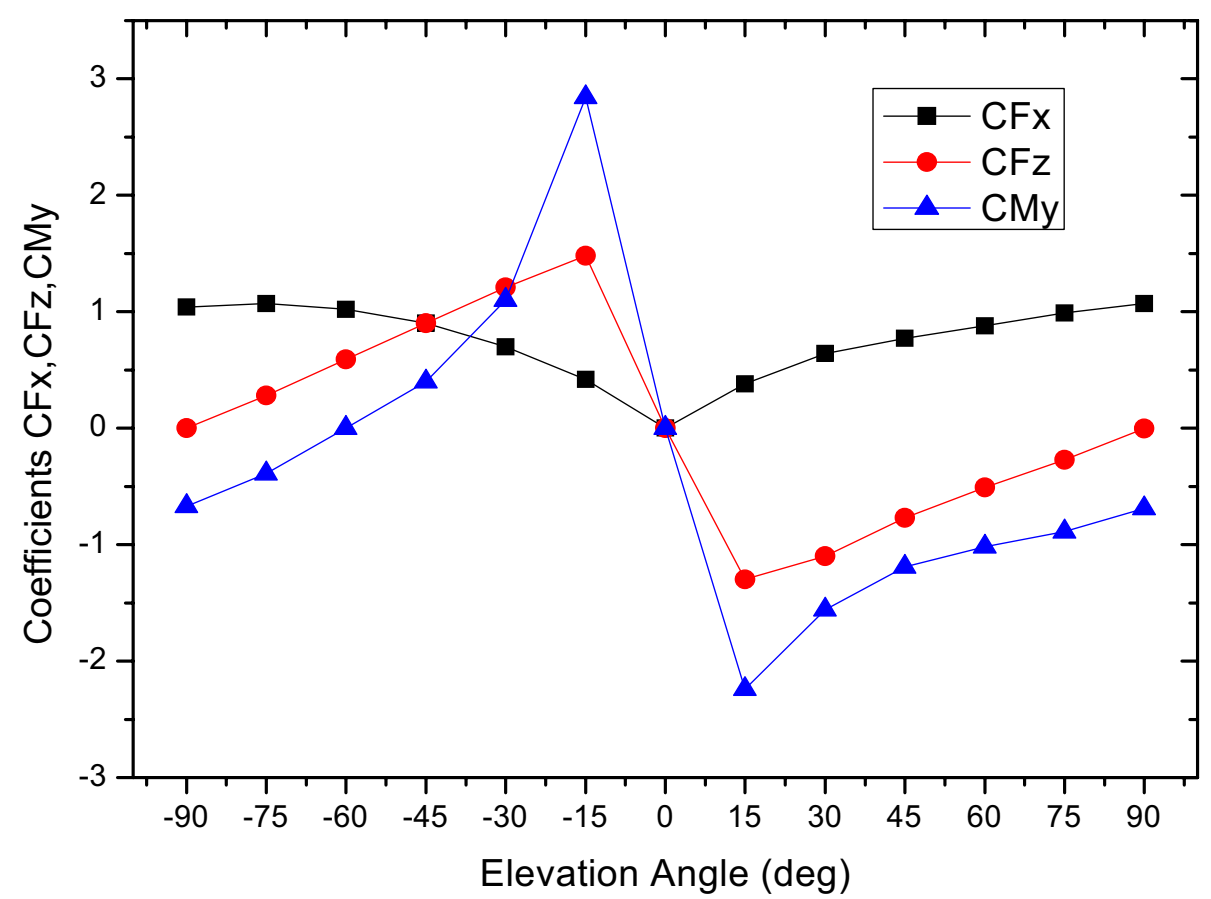

Fig. 8. Drag, lift, moment mean coefficients at different elevation angles for full-scale heliostat.

Table 1. Drag pressure Force $F x(N)$ for different elevation angles and reference velocities

\begin{tabular}{|c|c|c|c|c|}
\hline \multirow[b]{2}{*}{ Elevation Angle (deg) } & \multicolumn{4}{|c|}{ Drag Force $F x(N)$} \\
\hline & Velocity $5\left(\mathrm{~m} . \mathrm{s}^{-1}\right)$ & Velocity $10\left(\mathrm{~m} . \mathrm{s}^{-1}\right)$ & Velocity $15\left(\mathrm{~m} . \mathrm{s}^{-1}\right)$ & Velocity $20\left(\mathrm{~m} . \mathrm{s}^{-1}\right)$ \\
\hline-90 & 19853 & 7937 & 17799 & 31568 \\
\hline-75 & 1968 & 7869 & 17601 & 31102 \\
\hline$-60^{\circ}$ & 1698 & 6794 & 15285 & 27069 \\
\hline$-45^{\circ}$ & 1220 & 4882 & 10987 & 19505 \\
\hline$-30^{\circ}$ & 677 & 2710 & 6098 & 10799 \\
\hline$-15^{\circ}$ & 212 & 848 & 1910 & 3396 \\
\hline $0^{\circ}$ & 15 & 58 & 131 & 234 \\
\hline $15^{\circ}$ & 190 & 762 & 1715 & 3050 \\
\hline $30^{\circ}$ & 622 & 2489 & 5601 & 9959 \\
\hline $45^{\circ}$ & 1048 & 4192 & 9432 & 16744 \\
\hline $60^{\circ}$ & 1475 & 5900 & 13220 & 23312 \\
\hline $75^{\circ}$ & 1826 & 7341 & 16371 & 29026 \\
\hline $90^{\circ}$ & 2033 & 8132 & 18252 & 32399 \\
\hline
\end{tabular}

Table 2. Lift pressure Force $F z(N)$ for different elevation angles and reference velocities.

\begin{tabular}{|c|c|c|c|c|}
\hline \multirow{2}{*}{ Elevation Angle (deg) } & \multicolumn{4}{|c|}{ Lift Force $F z(N)$} \\
\hline & Velocity $5\left(\mathrm{~m} \cdot \mathrm{s}^{-1}\right)$ & Velocity $10\left(\mathrm{~m} . \mathrm{s}^{-1}\right)$ & Velocity $15\left(\mathrm{~m} \cdot \mathrm{s}^{-1}\right)$ & Velocity $20\left(\mathrm{~m} . \mathrm{s}^{-1}\right)$ \\
\hline$-90^{\circ}$ & -3 & -13 & -31 & -55 \\
\hline$-75^{\circ}$ & 526 & 2104 & 4704 & 8309 \\
\hline$-60^{\circ}$ & 980 & 3922 & 8824 & 15627 \\
\hline$-45^{\circ}$ & 1223 & 4896 & 11019 & 19557 \\
\hline$-30^{\circ}$ & 1171 & 4686 & 10543 & 18652 \\
\hline$-15^{\circ}$ & 756 & 3028 & 6814 & 12115 \\
\hline $0^{\circ}$ & 79 & 320 & 722 & 1286 \\
\hline $15^{\circ}$ & -664 & -2660 & -5989 & -10649 \\
\hline $30^{\circ}$ & -1065 & -4261 & -9588 & -17046 \\
\hline $45^{\circ}$ & -1048 & -4194 & -9436 & -16749 \\
\hline $60^{\circ}$ & -857 & -3429 & -7686 & -13553 \\
\hline $75^{\circ}$ & -495 & -1990 & -4442 & -7880 \\
\hline $90^{\circ}$ & -2 & -10 & -24 & -44 \\
\hline
\end{tabular}




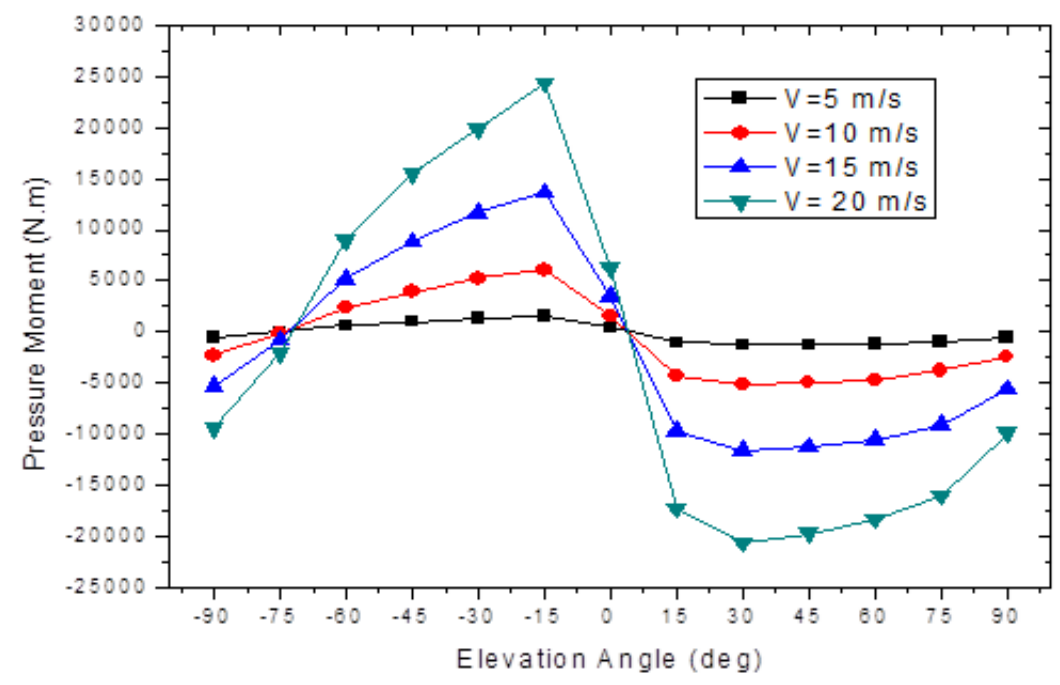

(a)

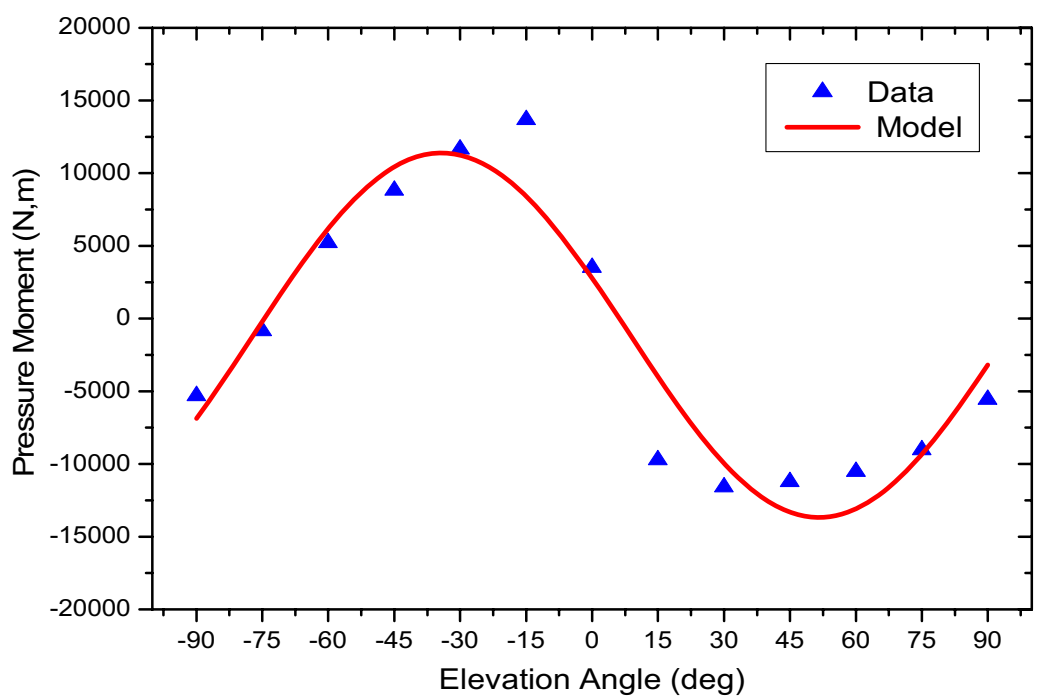

(b)

Fig. 9. (a) Mean pressure moment for different elevation angles and reference velocities. (b) Regression model plot of mean pressure moment at constant reference velocity $V=15 \mathrm{~m} \cdot \mathrm{s}^{-1}$.

The lift force is considerably anti-symmetric with the change of elevation angle. As we mentioned before, the effect of the torque tube is more apparent for the vertical force $F_{z}$ than for the horizontal force $F_{x}$. The lift force has the minimum at the elevation angles $-90^{\circ}, 0^{\circ}, 90^{\circ}$ and the maximum value occurs at $-45^{\circ}, 30^{\circ}$ for all wind speeds.

\subsection{Mean pressure moment}

Figure 9a represents the mean pressure moment at different elevation angles and wind speeds for the heliostat at real scale. The elevation angle is chosen from the range $-90^{\circ}$ to $90^{\circ}$ and the reference wind speeds are $5,10,15$, and $20 \mathrm{~m} \cdot \mathrm{s}^{-1}$.
The mean value of the pressure moment for stow position $\alpha=0^{\circ}$ is not nil, for example, $M_{y}\left(0^{\circ}\right)=390$, $1560,3509,6238 \mathrm{Nm}$ for reference wind speeds 5, 10, 15, $20 \mathrm{~m} . \mathrm{s}^{-1}$ respectively. As will be shown later, the effect of the wind forces and pressure moment at stow position will be presented separately.

In general, the influence of the torque tube is considerable big at negative angles $-90^{0} \leq \alpha \leq 0^{0}$, where the torque tube is in the front of the heliostat opposite the wind attack. The effect is more noticeable at elevation angles of about $-90^{\circ},-75^{\circ},-15^{\circ}$ degrees $[18,21]$.

For positive elevation angles $0^{0} \leq \alpha \leq 90^{\circ}$, the pressure distribution of wind forces on the upper part of the mirror plane is completely smaller than the lower part, which causes a high moment about the elevation axis in the negative direction. 
Table 3. Results of regression analysis of the mean pressure moment $M_{y}$ at different reference velocities.

\begin{tabular}{ccccc}
\hline Model coefficients & $V=5\left(\mathrm{~m} . \mathrm{s}^{-1}\right)$ & $V=10\left(\mathrm{~m} \cdot \mathrm{s}^{-1}\right)$ & $V=15\left(\mathrm{~m} . \mathrm{s}^{-1}\right)$ & $V=20\left(\mathrm{~m} . \mathrm{s}^{-1}\right)$ \\
\hline$\alpha_{0}$ & 94.48 & 94.14 & 94.45 & 94.36 \\
$w$ & 85.97 & 85.74 & 85.76 & 85.59 \\
$a$ & 1393.86 & 5557.37 & 12534.10 & 21972.11 \\
$M_{y 0}$ & -122.83 & -475.35 & -1143.89 & -2123.79 \\
$R^{2}$ & 0.91526 & 0.91416 & 0.91439 & 0.90997 \\
\hline
\end{tabular}

From Figure 9a, the mean value of pressure moment is nil at two angle positions, $\alpha=3.5^{\circ},-73^{\circ}$, this two elevation angles represent balance positions for the acting mean pressure forces. Thus, The known stow position $\alpha=$ $0^{\circ}$ is not the optimum position especially with high wind speed, because at this elevation angle $\alpha=0^{\circ}$ the hinge axis may have rotating moment of $M_{y}\left(0^{\circ}\right)=5000 \mathrm{Nm}$ for wind speed of $20 \mathrm{~m} . \mathrm{s}^{-1}$. This value is relatively small with respect to the maximum value $M_{y}\left(-15^{\circ}\right)=25000 \mathrm{Nm}$, but it represents also the maximum value at wind speed of $10 \mathrm{~m} \cdot \mathrm{s}^{-1}$ (Fig. 9a). Hence, the mean pressure moment at the known stow position $\alpha=0^{\circ}$ is not negligible for high values of wind speed.

The maximum value of the absolute pressure moment of the elevation angle $\alpha=-15^{\circ}$ is bigger than the one of $\alpha=30^{\circ}$. At this angle $\alpha=-15^{\circ}$ the back side of the mirror plane and the torque tube became in the front of the heliostat increasing the recirculation of air, and this make pressure bigger in the upper region of the back side.

The mean pressure moment $M_{y}$ of the heliostat depends mainly to the elevation angle, wind velocity and torque tube dimension. The interaction of these parameters makes the regression analysis hardly possible by using all the above parameters in one equation, and more data are needed to establish general model.

Supposing the torque tube effect is independent to the elevation angle, it becomes possible to describe how the interaction of these parameters influence the mean pressure moment $M_{y}$ at constant wind velocity. Therefore, the following non-linear model is used to capture the dependence of mean pressure moment to the elevation angle $\alpha$ :

$$
M_{y}(\alpha)=M_{y 0}+a \sin \left(\pi \frac{\alpha-\alpha_{0}}{w}\right)
$$

Coefficients of Equation (19) are determined from the regression analysis and given in Table 3 at different reference velocities.

The $R^{2}$ values are calculated to show the precision of established model. Since these values $R^{2}$ are close to 1 for pressure moment $M_{y}$, the used regression model represents the curve with acceptable accuracy (see Fig. 9b).

\subsection{Stow position $\left(\alpha=0^{\circ}\right)$}

Heliostats are either tracking the sun (normal operation) or assume a stationary downward facing attitude called the stow position (at night or during cloudy or very windy periods).
During strong wind, where the structure strength might be a concern, the solar collectors are typically rotated to stow position with the mirror facing up to reduce wind loads and to prevent the reflective surface from being damaged [4].

Sufficient data were obtained by simulation to provide load data for structural analysis in stow mode.

For the stow position, the mean forces and moment corresponding to low and very high reference wind speeds, $5,10,15,20,25,40,50$ m.s ${ }^{-1}$, were computed. The results are shown in Figure 10.

From Figure 10 the mean drag force $F_{x}$, mean lift force $F_{z}$ and mean moment $M_{y}$ reach their maximal values at storm conditions. Thus, their values at stow position are relevant to protect the mirror plane and the effect of torque tube is more apparent.

The difference between lift force $F_{z}$ and drag force $F_{x}$ increases with increasing wind velocity. This is caused by the horizontal position of mirror plane, where the lift force $F_{z}$ contributes significantly to rotate up the plane mirror.

Mean pressure moment has an important values at high wind speed, for example, $M_{y}(30)=14034 \mathrm{Nm}$, $M_{y}(40)=24946 \mathrm{Nm}, M_{y}(50)=38974 \mathrm{Nm}$. This confirms that the known stow position $\alpha=0^{\circ}$ is not the optimum stow position especially with high wind speed. Hence, the torque tube has a significant effect on the choice of stow position to minimise moments.

\subsection{Pressure field effect on heliostat wind loads}

The variations of the mean wind load coefficients can clearly be understood if the pressure field flow is studied. Figure 11 shows pressure contour diagrams for reference wind velocity $V=15 \mathrm{~m} . \mathrm{s}^{-1}$ at different elevation angles $90^{\circ}, 60^{\circ}, 30^{\circ}, 0^{\circ},-30^{\circ},-75^{\circ}$ for full-scale heliostat. As expected, there are regions of high pressure on the windward side of the collector and regions of low pressure on the leeward side.

The pressure field around the mirror plane of the heliostat is shown and the shear layer is clearly observed. The shear layer includes the separation zone depend mainly on the elevation angle [22].

A large separated zone is observed at $\alpha=90^{\circ}, 60^{\circ}$, $-75^{\circ}$, the turbulent flow in the detached region produces a large depression region in the leeward side being the responsible for the large value of drag coefficient obtained. The shear layer is more elevated at these positions; presumably, it is caused by a turbulence structure 


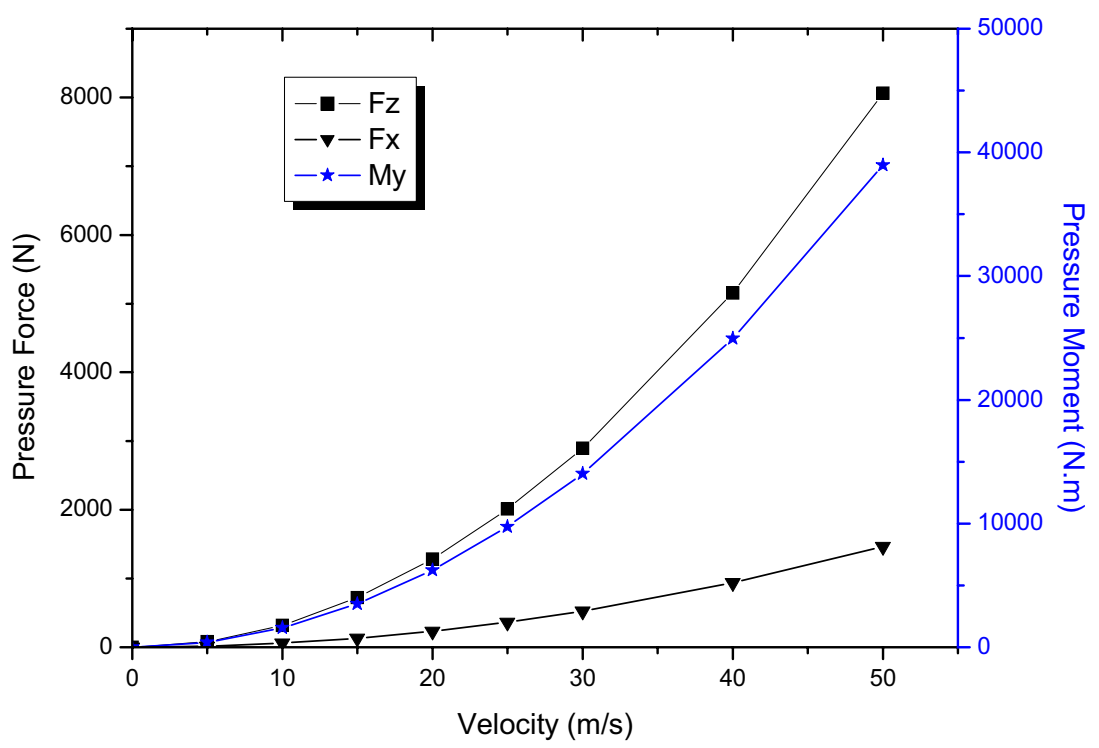

Fig. 10. Mean pressure forces and moment for low and high reference velocities at stow position $\left(\alpha=0^{\circ}\right)$.

that just hits the mirror plane there [14]. At elevation angle $\alpha=90^{\circ}$, the heliostat receives the maximum drag forces and minimum lift forces due to the shape of the mirror plane.

By changing the elevation angle from $\alpha=90^{\circ}$ to $\alpha=0^{\circ}$, the depression region is continuously reduced, which provokes a reduction of drag forces on the heliostat surface. At elevation angle of $\alpha=0^{\circ}$, only a small depression region is formed within the torque tube and mirror plane region. This is a good position for the protection of heliostat, when the mirror plane is aligned with the free-stream direction; but it is not the optimum position (see Fig. 9). The flow is completely attached to the mirror surface which provokes the reduction of the gradient pressure as well as the reduction of drag forces.

By moving the elevation axis from $\alpha=0^{\circ}$ to $\alpha=$ $-90^{\circ}$, a large recirculation zone with low pressure is formed in the leeward side of the flow and the drag forces increase again.

\section{Conclusion}

The goal of the present study was to perform numerical simulations of the air flow around an isolated heliostat of solar tower at real scale, in order to provide a quantitative assessment of mean wind loads. The accuracy of the numerical model is verified on a heliostat model at wind tunnel scale. Results of the adopted meshing method and the turbulence $k-\varepsilon$ model matched reasonably well with the wind tunnel data, improving our confidence in using CFD for other analyses.

The same numerical simulation method was performed on full-scale model of heliostat to estimate mean load coefficients (drag, lift, and moment coefficients), mean pressure forces, mean pressure moment and static pressure field.
These simulations show the interaction between the wind speed and the elevation angle of heliostat at real scale, and can be used to determine the acting forces. The results help to understand the aerodynamic behaviour and loading of our heliostat design.

The results revealed the following facts:

- The effect of horizontal torque tube on wind loads coefficients was significant. It is more apparent for the lift force than for the drag force and does not necessarily worsen the wind loads.

- The torque tube has a significant effect on the choice of stow position to minimise moments.

- The mean value of pressure moment has the minimum at elevation angle $\alpha=3.5^{\circ}$, this angle represents equilibrium positions for the acting mean pressure forces. Therefore, the known stow position $\alpha=0^{\circ}$ is not the optimum position especially with high wind speed.

- It is well knowing that the actual peak pressure moment is not zero at any stow position, as the mean value is, because of turbulence in wind, and bodygenerated turbulence. Hence, it will be very important to examine the peak fluctuating wind loads at the stow position $\alpha=3.5^{\circ}$ in the next works.

- The acting mean forces and moments on heliostat at full-scale are very big at the extreme angles and velocities. In order to know how the exerted forces and moments become practically inacceptable from operational standpoint, the analysis of the structural mounting system of the heliostat should be studied.

Wind loads on heliostat at high Reynolds number has many work prospects. The unsteady (dynamic) wind load at real scale, generated mainly by the unsteady vortices behind the mirror plane of heliostat, is also important in the heliostat design. The stiffness and damping of a heliostat structure must be high enough to avoid wind-induced torsional divergence, flutter, and resonance of the structure. Unsteady wind loading has the potential to cause 

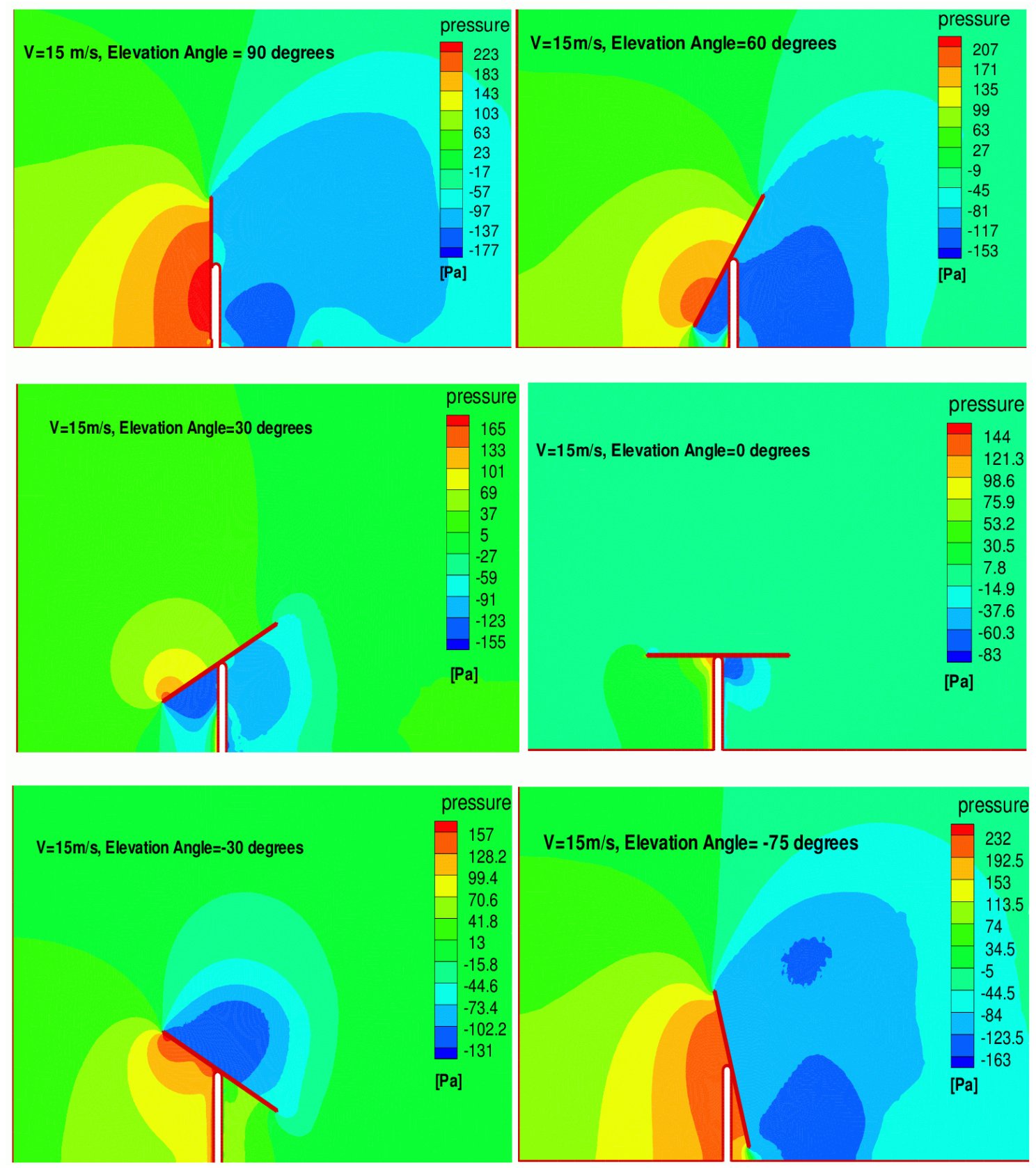

Fig. 11. Pressure contour diagram for different elevation angles.

structural failure, tracking errors, optical losses, and reduction of heliostat life [23].

Measurements in a high-pressure wind tunnel could allow the comparison with numerical results of this study. The air can be pressurized to increase its density which leads to sufficiently high Reynolds number [7]. However, a huge wind tunnel for measurements at real scale is not available.

Field measurements in open terrain is still considered also to be the most reliable method for evaluating wind loads at real scale [24]. Nevertheless, the appearance of the needed wind speeds is random and not predictable which make the comparison very difficult.
Understanding the aerodynamic behaviour and loading of our heliostat design enabled systems to be designed to avoid the cost of the heliostat damage and failure. However, wind loads on a single heliostat are informative for characterizing the baseline performance.

\section{References}

[1] A. Pfahl, M. Buselmeier, M. Zaschke, Wind loads on heliostats and photovoltaic trackers of various aspect ratios, Sol. Energy 85 (2011) 2185-2201

[2] NASA Ames Fluid Mechanic Laboratory, Heliostat Wind Tunnel Experiments, 2011 
[3] Z. Wu, B. Gong, Z. Wang, Z. Li, C. Zang, An experimental and numerical study of the gap effect on wind load on heliostat, Renew. Energy 35 (2010) 797-806

[4] B. Gong, Z. Li, Z. Wang, Y. Wang, Wind-induced dynamic response of Heliostat, Renew. Energy 38 (2012) 206-213

[5] J.A. Peterka, R.G. Derickson, Wind load design methods for ground-based heliostats and parabolic dish collectors, NASA STIRecon Tech. Rep. N 93 (1992)

[6] A. Pfahl, M. Randt, C. Holze, S. Unterschütz, Autonomous light-weight heliostat with rim drives, Sol. Energy 92 (2013) 230-240

[7] A. Pfahl, H. Uhlemann, Wind loads on heliostats and photovoltaic trackers at various Reynolds numbers, J. Wind Eng. Ind. Aerodyn. 99 (2011) 964-968

[8] Z. Wu, Z. Wang, Numerical study of wind load on heliostat, Prog. Comput. Fluid Dyn. Int. J. 8 (2008) 503-509

[9] Z. Aishe, L. Zhang, J. Zhou, Numerical simulation of wind environment around two adjacent buildings, Chin. J. Comput. Mech. 5 (2003) 44-49

[10] W. Miao, Applications of CFD in the Moving Boundary Condition and Great Truss Beam Structure, Master Thesis, Peking University, Beijing, 2006

[11] B. Blocken, T. Defraeye, E. Koninckx, J. Carmeliet, P. Hespel, CFD simulations of the aerodynamic drag of two drafting cyclists, Comput. Fluids 71 (2013) 435-445

[12] T. Defraeye, B. Blocken, J. Carmeliet, CFD analysis of convective heat transfer at the surfaces of a cube immersed in a turbulent boundary layer, Int. J. Heat Mass Transf. 53 (2010) 297-308

[13] ESI Group CFD Portal - Guidelines for Specification of Turbulence at Inlet Boundaries. [Online]. Available: http://www.esi-cfd.com/content/view/877/192/ [Accessed: 05-May-2016]

[14] A.A. Hachicha, I. Rodríguez, J. Castro, A. Oliva, Numerical simulation of wind flow around a parabolic trough solar collector, Appl. Energy 107 (2013) 426-437
[15] M.K. Zemler, G. Bohl, O. Rios, S.K.S. Boetcher, Numerical study of wind forces on parabolic solar collectors, Renew. Energy 60 (2013) 498-505

[16] J. Peterka, N. Hosoya, B. Bienkiewicz, J. Cermak, Wind Load Reduction for Heliostats, Solar Energy Research Institute, 1986

[17] S.M. Boudia, A. Benmansour, M.A. Tabet Hellal, Assessment of Coastal Wind Energy Resource,Two Locations in Algerian East, Int. J. Energy Sci. 3 (2013)

[18] N. Hosoya, J.A. Peterka, R.C. Gee, D. Kearney, Wind Tunnel Tests of Parabolic Trough Solar Collectors

[19] M.E.A. Slimani, M. Amirat, S. Bahria, I. Kurucz, M. Aouli, R. Sellami, Study and modeling of energy performance of a hybrid photovoltaic/thermal solar collector: Configuration suitable for an indirect solar dryer, Energy Convers. Manag. (2016)

[20] S. Bahria, M. Amirat, A. Hamidat, M. El Ganaoui, A. Khoudja, Study of the solar combisystems for different types of building construction in Algiers climate, in Renewable and Sustainable Energy Conference (IRSEC), 2014 International, 2014, pp. 778-781.

[21] S. Bahria, M. Amirat, A. Hamidat, M. El Ganaoui, M. Slimani, Parametric study of solar heating and cooling systems in different climates of Algeria - A comparison between conventional and high-energy-performance buildings, Energy 113 (2016) 521-535

[22] J.A. Peterka, L. Bienkiewicz, Cermak, Mean and Peak Wind Load Reduction on Heliostat, Solar Energy Research Institute, 1987

[23] J. Coventry, J. Pye, Heliostat Cost Reduction - Where to Now?, Energy Procedia 49 (2014) 60-70

[24] B. Gong, Z. Wang, Z. Li, J. Zhang, X. Fu, Field measurements of boundary layer wind characteristics and wind loads of a parabolic trough solar collector, Sol. Energy 86 (2012) 1880-1898 